\title{
О.М. Краснорядцева
}

Томский государственный университет (Томск, Россия)

\section{Образовательный опыт развития рефлексии в структуре личностных компетенций студентов, обучающихся менеджменту}

\begin{abstract}
Рассмотрены возможности рефлексивного семинара как способа организачии образовательных событий, направленных на формирование навыков рефлексии в структуре личностных компетенций студентов, обучаюшихся менеджменту. На эмпирическом материале проиллюстрировано, как высокий уровень развития рефлексии проявляется в перестройке поведения u деятельности, смыслообразовании $u$ перестройке смыслов, поиске вариативных способов решения конкретных проблем, в актах включения человека в творческие прочессы, прочессы самореализации. В исследовании в качестве методического инструментария использован ряд опросных методик, позволяюших зафиксировать динамику личностных изменений участников семинара. Обсуждены полученные данные о феномене иентрации-децентрации, являющемся необходимым условием актуализачии готовности к пониманию других и себя.
\end{abstract}

Ключевые слова: рефлексия, личностная компетентность; «центрация децентраиия»; образовательные эффекты; актуализация; рефлексивный семинар.

В настоящее время в российской университетской образовательной среде интенсивно происходят изменения в связи с реализацией идей компетентностного подхода, одним из значимых результатов реализации которого является сформированная профессиональная позиция выпускника вуза. По мнению ряда российских специалистов (Г.А. Воробьева, П.А. Жильцов, Л.П. Жуйкова, Р.Г. Каменский, И.А. Колесникова, С.И. Краснов, А.А. Леонтьев, И.А. Маврина, А.К. Маркова, Н.Б. Нестерова, Я.Ф. Ратц, В.И. Слободчиков, Р.С. Соломатина, Г.В. Судольский, М.П. Целых, Н.Е. Щуркова, Е.Г. Юдина и др.), профессиональная позиция представляет собой:

- продукт педагогического мышления;

- следствие осознанного природного образовательного процесса;

- единство профессионального сознания, профессиональной деятельности, профессиональных отношений;

- ответственное отношение к ценностям и способам реализации деятельностных норм;

- устойчивый феномен сознания, определяющий тот тип взаимодействия с учащимися, который будет реализован педагогом в его педагогической деятельности. 
Профессиональная позиция, опирающаяся на системно усложняющуюся в ходе развития человека личностную компетентность, выступает значимым индикатором, отражающим динамику профессионального самоопределения. Личностная компетентность является внутренним динамическим фактором профессиональной (образовательной) компетентности, структурирующим разворачивание деятельности, придающим ей направленность; представляет собой ценностно-смысловую надстройку над специальной компетентностью, обеспечивает становление человека за пределами образовательного учреждения и обусловливает перевод учебной деятельности в образовательную. Личностная компетентность в значительной степени определяет индивидуальный профессиональный метод, стиль профессиональной деятельности, обеспечивающий дальнейшее становление, самореализацию в труде. Сердцевину личностной компетентности составляет то, насколько человек может отрефлексировать смысл и ценность своей деятельности, своего труда [1-4]. Речь здесь идет не только о динамике смыслообразующих мотивов, релевантных деятельности, но и о мотивообразующих смыслах, переводящих любую актуальную деятельность в самосозидательную (образовательную, творческую) [5, 6].

В течение ряда лет под нашим руководством были проведены опросы студентов и аспирантов разных факультетов Томского государственного университета о тех трудностях, которые они испытывают при переходе к образовательной системе, ориентированной на развитие тех или иных компонентов профессиональной компетентности [7, 8]. Наиболее часто молодые люди указывают на проблемы в организации собственной деятельности, отсутствие позитивного опыта как в проектировании индивидуальной образовательной стратегии, так и в накоплении информации, отражающей индивидуально-личностное движение студентов в период обучения в университете.

В этой связи чрезвычайно важным представляется поиск способов происходящей непосредственно в образовательном процессе актуализации образовательных эффектов, свидетельствующих о реально существующей динамике процессов саморазвития, самореализации, профессионального и жизненного самоопределения студентов. Одним из продуктивных способов такой актуализации являются специально организованные формы развития рефлексии как механизма оценки человеком своего жизненного мира, его ценностно-смыслового состава и изменений, происходящих в нем.

\section{Процедура и метод}

Исследования проводились в рамках межфакультетского образовательного проекта для студентов старших курсов «Менеджмент инновационных проектов» и со студентами 4-го курса факультета психологии Томского государственного университета, обучающимися по специальности «управление персоналом», в течение 2011-2014 гг. Общий объем выборки составил 126 человек (6 учебных групп). Образовательной формой, по- 
средством которой осуществлялось развитие рефлексии студентов, был выбран рефлексивный семинар. Продолжительность семинара варьировалась от 3 до 6 месяцев с периодичностью 1 раз в 2 недели.

Основные задачи рефлексивного семинара:

- развитие навыков рефлексии динамики собственных личностных изменений;

- развитие рефлексии готовности и способности к презентации себя партнерам по совместной проектной деятельности и к пониманию поведенческих реакций партнеров.

Процедура рефлексивного семинара предусматривала три этапа:

1. На первом этапе студентам предлагалось оценить (с помощью соответствующих балльных шкал) степень выраженности у себя ряда профессионально значимых для менеджера качеств, а затем сравнить свою оценку с реальными данными, полученными психологами на предварительном тестировании. На этом этапе были использованы широко распространенные при работе с менеджерами тесты «Коммуникативный минимум менеджера», «Определение креативного потенциала», «Якоря карьеры» [9], «Опросник SACS (стратегии преодоления стрессовых ситуаций)» (С. Хобфолл). Предметом групповой рефлексии на данном этапе были представление о себе и самооценка.

2. На втором этапе каждому студенту предлагалось написать на доске три качества, которые, по его мнению, ему удается проявлять непосредственно в ходе учебной, исследовательской, проектной деятельности в университете, и три качества, которые, по его мнению, он может адекватно оценить у других членов группы. Затем путем группового обсуждения были выделены 10 личностных качеств, которые чаще всего назывались по обоим выделенным основаниям участниками семинара. Далее студентам было предложено оценить степень выраженности этих качеств как у себя, так и у всех членов группы. Особо оговаривалось условие, что каждый оценивает только те качества, для оценки которых у него есть реальные основания, и не оценивает те, оценить которые на данном этапе взаимодействия ему не представляется возможным.

3. На третьем этапе был проведен цикл занятий, имеющих форму рефлексивных семинаров, в ходе которых обсуждались проблемы самореализации личности. Каждому студенту давалась возможность представить обоснование того, в каких жизненных сферах проявляется его самореализация. Важным моментом этих бесед было обсуждение того, какой видят студенты свою будущую жизнь, какие ценности и жизненные сферы будут для них значимы и значимы сейчас, каково их понимание будущего.

По окончании этого этапа было проведено повторное оценивание тех же качеств у себя и у других членов группы. 


\section{Результаты}

На первом этапе рефлексивного семинара фиксировались особенности осмысления студентами себя в качестве субъекта деятельности путем решения задач «на смысл», которые формировались в ходе сопоставления своих субъективных оценок с данными, полученными в результате тестирования. Нижепредставленные поведенческие реакции студентов можно считать типичными для данной выборки, поскольку в целом реакции остальных участников семинара при всем индивидуальном разнообразии поведенческого репертуара (в своих вербальных и невербальных средствах выражения) схожи с описанными.

Участница семинара $A$.

A.: Ой, ужас какой! Я, оказывается, совсем не креативная! Нет, это правда ужас! ...Я сейчас не готова что-либо сказать... Я потом... После других... (покраснела, прижала руки к щекам, глаза опущены вниз).

Ведущий: Вы не ожидали такого расхождения в оценке креативности?

A.: Это правда неожиданно... И так намного... Ну, ладно, там по карьерным ориентациям расхождения большие, это я еще понимаю, а... по креативности... это же обидно... (не может успокоиться, все время теребит листок).

Ведущий: Вас волнует расхождение в оценках только по креативности или и по другим показателям?

A.: ...Да, по другим тоже как-то... но по креативности, это просто удар! (смеется)... Вот так, оказывается, можно заблуждаться. ты была!

C.: Да что тебе эта креативность далась! Мало ли в каком состоянии

A.: Нет, ты не понимаешь!.. Может быть, я действительно не понимаю, что это такое... хотя... нет, правда, я себя считала всегда очень творческим человеком... А знаете, можно будет посмотреть еще раз вопросы... и как это... интерпретацию... Может быть, там какая-то ошибка... нет, я не про то, что плохо подсчитали или ошиблись... а может быть, я что-то не поняла... все-таки мне не верится, что я такая некреативная оказалась... С этим ведь надо что-то делать...

Ведущий: Что-то делать с результатами?

A.: Да нет... конечно, не с результатами... а со мной... если это действительно так, то ведь нужно как-то пересмотреть... в общем, я, кажется, понимаю, над чем мне стоит подумать...

В данном случае мы реально наблюдаем, как обнаруженный разрыв в сложившемся представлении студентки о собственной креативности и результатах, полученных при тестировании, актуализирует потребность в рефлексии по поводу собственной Я-концепции, переосмысления позиции в самооценке. 
Участник семинара $K$.

$K .:$ Вот так я приблизительно и думал... Основные расхождения по моим проблемным точкам... Это импульсивные действия... агрессивные действия... вызов... Я предполагал, что этого у меня достаточно... но оказывается, что просто зашкаливает...

Ведущий: Ну почему зашкаливает? Ваши результаты по этим шкалам на границе между средней и высокой степенью выраженности.

K.: Но ведь они самые высокие среди всех других!

Ведущий: Вас это огорчает?

$K .:$ Еще как! Это по жизни моя проблема... Сначала сделаю, а потом думаю, зачем...(смеется) Что поделаешь, генетика... я ж наполовину южный человек... темперамент горячий (выразительно машет руками).

Ведущий: Возможно, вы найдете у себя какие-то ресурсы, которые могут компенсировать избыточную импульсивность?

$K .:$ Ищу все время... я же сделал для себя выбор - хочу стать успешным менеджером! ...Значит надо обретать... как вы это называли... коммуникативную компетентность!

Д.: Ну, знаешь, с природой бороться чревато...

$K .:$ Нет, не бороться... я это понимаю... сейчас... сформулирую... надо научиться это переводить... знаете, как говорят, «его недостатки - это продолжение его достоинств». ...У Меня это пока получается только с девушками (смеется)... буду учиться... не думал, что так поймаюсь... старался же быть объективным... но, видно, на то и проблемы, чтобы думать... буду думать...

В данном случае студент наглядно демонстрирует в своих реакциях собственное движение к выделению проблемной для него «зоны личностного развития», актуализирует необходимость переформулировки данной личностной проблемы как проблемы саморазвития.

Участница семинара Ю.:

Ю.: А у меня... наоборот... я даже не ожидала... такая большая креативность... удивительно... и главное, общая креативность высокая!

Ведущчий: Это вас сильно удивило?

Ю.: Конечно!... Ну, там настойчивость, целеустремеленность, этого у меня в избытке... а креативность... как-то не сильно я это замечала (высоко поднимает брови, пожимает плечами).

$E .:$ По-моему, ты не права!.. на деловой игре и тренинге я что-то не заметила у тебя недостатка в креативности.

Ю.: Да нет, на самом деле я страшно довольна!.. Правда, это здорово!... хотя и неожиданно... а может, у меня самооценка заниженная?...

Ведущиии: А как вы сами думаете?

Ю.: Да есть, наверное, немного... вот смотрите, по шкале «Уверенность в поведении» я себя оценила ниже, чем получилось по тестам... по осторожным действиям также... надо менять отношение к себе... вообщето я понимаю, откуда это... это негативный школьный опыт... четвертый год пытаюсь избавиться от этого атавизма... но, видно, еще не до конца... 
знаете, очень вовремя этот проект появился! Есть хорошая возможность поработать над собой...

Здесь мы видим вариант своеобразного когнитивного диссонанса, переживаемого студенткой и вызванного возникшим рассогласованием между представлениями о собственной креативности и данными тестирования. И это переживание актуализирует имеющийся у нее опыт недооценки себя («негативный школьный опыт») и выводит к необходимости переосмысления понимания себя.

Участник семинара $M$.

M.: Ну, что я могу сказать... никаких особых потрясений я не испытал... в целом примерно так я себя и оцениваю, как и получилось в тестах...

Ведущзии: И ничего для себя вы нового не отметили?

M.: Ну, почему?... Есть вещи, про которые я раньше не думал... ну, вот, например... стратегии преодолевающего поведения... интересно действительно сопоставить разные стратегии... я такими категориями не мыслил... а тут так получилось, что я первый раз оценивал себя по таким параметрам и сразу же попал... практически все совпадает с данными... по степени, конечно, а не по абсолютным значениям...

Ведущий: Может быть, какие-то результаты были для вас неожиданными?

M.: Неожиданными?.. Пожалуй, да... Ориентация на интеграцию стилей жизни... Она как-то доминирует среди других... И интересно, что и я ее высоко оценил у себя.... Хотя раньше так прямо об этом не думал... Знаете, эта работа дает импульс для самоанализа... появляются как бы другие ракурсы... определенно, это полезно для меня...

В описанном случае мы видим, как студент открывает для себя проблемное поле для самоанализа, актуализируя тем самым возможности в понимании себя.

По сути, в описанных иллюстративных фрагментах рефлексивного семинара представлены различные варианты проявления процесса актуализации потребности в саморазвитии, что и является образовательным эффектом данного этапа проекта. Зафиксированный феномен актуализации потребности в саморазвитии можно отнести к запланированному продуктивному результату образовательных проектов, в рамках которых были организованы рефлексивные семинары, поскольку и содержание, и формы организации профессиональной подготовки ориентированы, прежде всего, на активизацию потенциала саморазвития, профессионального самоопределения. Использованная форма актуализации рефлексивных усилий молодых людей по поводу выраженности у себя профессионально значимых личностных качеств обусловливает ревизию сложившихся установок, стереотипов, предпочтения и изменение их в той части, которая может быть осознана в специально организованных актах объективации.

На втором этапе рефлексивного семинара студенты достаточно аргументированно и обоснованно выделили следующие профессионально 
значимые характеристики менеджера: высокий уровень образованности и эрудиции (78\% ответивших); коммуникабельность, умение профессионально выстраивать систему взаимоотношений с людьми (98\%); высокоразвитая ответственность (82\%); аналитические способности $(86 \%)$; готовность к инновациям, гибкость к инновационным изменениям (94\%); развитое креативное, творческое мышление (82\%); готовность и умение принимать верные управленческие решения в нестандартных ситуациях (90\%); высокий уровень сформированности специальных управленческих умений (90\%); выраженные лидерские качества (80\%); умение работать в команде (76\%); умение конструктивно разрешать конфликты, находить выходы из конфликтных ситуаций (74\%); знание психологии и умение применять эти знания в практике общения с людьми (64\%); тактичность и дипломатичность (94\%); умение эффективно использовать власть (52\%); умение вести переговоры $(72 \%)$; высокая обучаемость и самообучаемость $(68 \%)$; решительность (80\%); умение четко и ясно выражать свои мысли (78\%); готовность и способность к риску (68\%); умение подчиняться, дисциплинированность (56\%); целеустремленность (62\%); инициативность (73\%); умение прислушиваться к мнению других (58\%); умение предвидеть, прогностические способности (76\%).

Студенты, обучающиеся в разных образовательных проектах, но в рамках одного направления подготовки «Менеджмент», в целом выделяют одни и те же профессионально значимые качества, необходимые менеджеру, что свидетельствует о достаточно сложившихся у них профессиональных представлениях о предполагаемом предмете рефлексии.

Однако можно констатировать и наличие некоторых особенностей в представлениях о современном менеджере у студентов, имеющих разный опыт вхождения в будущую профессию (на уровне прохождения «пассивной» или активной практики с частичным выполнением профессиональных функций; на уровне выполнения менеджерских функций в различных общественно-политических проектах или в различных видах организаторской деятельности; на уровне совмещения учебы с работой по специальности и т.п.).

1. В ответах студентов, имеющих опыт управленческой и организационной деятельности, часто встречается указание на такие профессионально значимые качества, как умение работать с информацией (42\%); вера в себя, в свои силы (14\%).

2. Только студенты, имеющие непосредственный опыт участия в профессиональной деятельности, называют такие умения и качества современного менеджера, как рефлексивность, стрессоустойчивость, умение видеть картину в целом, способность реально оценивать себя, толерантность, умение делегировать полномочия, способность к конструктивной критике.

3. Только студенты, имеющие опыт участия в организаторской деятельности, называют такие значимые, с их точки зрения, характеристики современного менеджера, как способность и умение выступать воспитате- 
лем по отношению к коллективу; умение сплачивать коллектив; гуманистический настрой.

4. Только в описаниях студентов, не имеющих опыта управленческой деятельности, встречаются указания на честность современного менеджера.

Предметом рефлексии непосредственно в ходе семинара стали полученные результаты в виде индивидуальных графиков самооценки и групповой оценки другими; усредненных и обобщенных данных по группе.

Обобщенные результаты индивидуальных графиков самооценки и групповой оценки другими представлены в табл. 1.

Т а бли ц а 1

\begin{tabular}{|l|c|c|}
\hline $\begin{array}{l}\text { Соответствие самооценки и } \\
\text { групповой оценки }\end{array}$ & $\begin{array}{c}\text { Участники межфакультет- } \\
\text { ского проекта, \% }\end{array}$ & $\begin{array}{c}\text { Студенты специальности } \\
\text { «управление персоналом», \% }\end{array}$ \\
\hline Выраженное соответствие & 4 & 7 \\
\hline $\begin{array}{l}\text { Тенденции похожи, но са- } \\
\text { мооценка выше }\end{array}$ & 32 & 45 \\
\hline $\begin{array}{l}\text { Самооценка значительно } \\
\text { превышает групповые } \\
\text { оценки }\end{array}$ & 16 & - \\
\hline $\begin{array}{l}\text { Самооценка значительно } \\
\text { ниже групповых оценок }\end{array}$ & 10 & 48 \\
\hline
\end{tabular}

В табл. 2 представлены усредненные результаты самооценки и оценки степени выраженности профессионально значимых для выпускника качеств.

Т а бли ц а 2

\begin{tabular}{|l|c|c|c|c|}
\hline \multirow{2}{*}{$\begin{array}{c}\text { Профессионально } \\
\text { значимые качества }\end{array}$} & \multicolumn{2}{|c|}{$\begin{array}{c}\text { Участники межфакультетско- } \\
\text { го проекта }\end{array}$} & \multicolumn{2}{|c|}{$\begin{array}{c}\text { Студенты специальности } \\
\text { «управление персоналом» }\end{array}$} \\
\cline { 2 - 5 } & усредненная & $\begin{array}{c}\text { Усредненная } \\
\text { оценка парт- } \\
\text { неров }\end{array}$ & $\begin{array}{c}\text { Усредненная } \\
\text { самооценка }\end{array}$ & $\begin{array}{c}\text { Усредненная } \\
\text { оценка партне- } \\
\text { ров }\end{array}$ \\
\hline Уверенность в себе & 8,0 & 6,5 & 8,5 & 8,24 \\
\hline Толерантность & 8,1 & 6,2 & 8,0 & 7,5 \\
\hline Доброжелательность & 8,5 & 6,5 & 8,7 & 7,6 \\
\hline Активность & 7,6 & 6,1 & 9,0 & 7,6 \\
\hline Аналитичность & 7,1 & 4,5 & 8,2 & 6,4 \\
\hline Ответственность & 8,4 & 5,2 & 8,4 & 7,0 \\
\hline Общительность & 8,2 & 6,1 & 8,1 & 6,9 \\
\hline Решительность & 7,4 & 5,1 & 7,6 & 6,1 \\
\hline Работоспособность & 8,0 & 5,1 & 8,6 & 7,4 \\
\hline Естественность & 8,1 & 6,4 & 8,3 & 5,9 \\
\hline
\end{tabular}

Полученные данные свидетельствуют о специфике социальной перцепции данной категории студентов при оценивании партнеров (в данном случае сокурсников), проявившейся в выраженной тенденции более низких 
оценок степени развития профессионально значимых качеств у других по сравнению с самооценкой.

На третьем этапе рефлексивного семинара были получены данные, позволяющие констатировать реальное углубление представлений студентов о существующих ограничениях в восприятии и понимании других людей; попытки поиска объяснения этому феномену; проявление готовности и способности к самовыражению в ситуациях совместной (групповой) деятельности, связанных с особенностями понимания себя, что проявилось в сближении позиций студентов с тем разбросом представлений, который был отмечен в начале работы семинара.

Ниже приведены отрывки из рефлексивных высказываний участников семинара.

Участник семинара $B$. : Да, все оказалось гораздо сложнее, чем представлялось вначале... представляете, я вдруг неожиданно для себя понял, что есть люди в нашей группе, которых я просто не вижу... смотрел сейчас на них, когда надо было оценивать качества, и не мог вспомнить ни одной ситуации деловой игры... или тренинга, где бы я их запомнил... это удивительно, но факт... а ведь казалось, что вижу всех... особенно ярко было это ощущение, что вижу всех на деловой игре... ведь мы все там были конкурентами, а для меня важно было понять, что являют собой другие, чтобы удачно простроить свою линию и выступления... и вот на тебе... ни одной картинки не могу восстановить про некоторых... а самое поразительное, что с троими из них мы на тренинге в одной подгруппе были... интересно, меня тоже кто-то не помнит и оценить не может?..

Участница семинара И.: Я хочу сказать, что это действительно непростое задание... я сначала попыталась оценить всех, а в конце стала оценивать себя... и меня как озарило, что я ведь, наверное, не смогла проявить все эти качества на занятиях... ну, так, чтобы их могли правильно оценить другие... в нашей группе есть такие ребята, которых оценивать легко... а вот со мной скорее всего будут проблемы... я как-то не думала, что мои качества кто-то будет оценивать не по тестам, как было при конкурсе... а по тому, как я веду себя на занятии... это необычно... и вот еще... один момент... я сейчас подумала... а может, для меня это так важно, потому что я не до конца уверена, что эти качества у меня развиты в достаточной мере?.. Может быть такое?.. И потом, у некоторых я не все качества смогла оценить...

Участник семинара $\Phi$.: А я, знаете, на что обратил внимание... что я могу оценить и, наверное, точно некоторые другие качества, которые не попали в список... хотя сам я писал на доске те, которые попали в список... наиболее ярко это ощущение было, когда нужно было дать самооценку... мне вдруг так захотелось оценить себя по креативности... а ее почему-то не оказалось в списке... интересно, да?.. И еще, я отметил для себя... есть разница в оценке других и себя самого... то есть я могу назвать те качества, которые я достаточно легко оценивал в других, а какие с большим трудом, а в некоторых случаях вообще не смог... и эти качества 
не совпадали с теми, когда я оценивал себя и чувствовал тоже... ну, то есть легко или с раздумьями... в общем, я проставил не по всем качествам баллы... что-то не смог, а придумывать ведь смысла нет...

Приведенные описания свидетельствуют о том, что студенты самостоятельно через рефлексию своих оценок, данных партнерам по группе и самому себе, выходят к выделению собственных особенностей в понимании себя и других.

Проведенный в конце третьего этапа семинара повторный срез особенностей самооценки и оценки партнеров по совместной профессионально ориентированной деятельности выявил интересные тенденции. Достаточно высокая самооценка, отражающая характерные для участников данных образовательных проектов притязания и амбиции, практически не изменилась. В то же время достаточно существенные изменения произошли в оценке профессионально значимых качеств своих партнеров по проекту в сторону более адекватной их оценки. Если на первом этапе рефлексивного семинара средние значения самооценки распределялись (по 10-балльной шкале) в диапазоне от 7,0 до 9,6, а оценки других - в диапазоне от 2,76 до 6,86 , то после окончания проекта оценки других возросли от 6,5 балла до 9,4, что в гораздо большей степени соответствовало реальной картине выраженности данных качеств у участников проекта.

К числу основных результатов рефлексивного семинара можно отнести следующие:

- у 16\% студентов участие в проекте привело к открытию в себе качеств, необходимых успешному менеджеру, что ранее не было предметом специальной рефлексии в жизненном опыте этих студентов;

- для 18,5\% студентов характерно расширение представлений о себе в контексте углубления представлений о соответствии уровню развития профессионально значимых личностных качеств успешных менеджеров;

- у $62 \%$ студентов можно наблюдать выраженную специфику представлений о динамике личностных изменений на данном этапе участия в проекте;

- у 3,5\% студентов можно констатировать некий когнитивный диссонанс, возникший на этом этапе участия в проекте между представлением о себе и соотнесением этого знания с представлениями о личности успешных менеджеров.

Анализ поведенческих реакций и высказываний студентов на этом этапе рефлексивного семинара позволил констатировать, что в процессе рефлексивных действий у студентов (по ходу самой процедуры оценивания) появляется особый образовательный эффект - актуализация готовности к пониманию поведенческих реакций партнеров и себя самого. Формы проявления этой готовности могут быть разные:

- как открытие для себя существующих ограничений в восприятии и понимании других людей и попыток дать свое объяснение этому феномену; 
- как самостоятельный выход к выделению собственных особенностей в понимании себя и других через рефлексию своих оценок, данных партнерам по группе и самому себе.

Интересен тот факт, что в окончательный список личностных качеств, которые, по мнению студентов, они и смогли презентировать партнерам, и готовы оценивать в партнерах по группе, входят практически все те указанные в ходе тренинга качества, которые необходимо развивать у себя, чтобы быть успешными менеджерами (толерантность, уверенность в себе, доброжелательность, ответственность, общительность, активность, решительность, работоспособность, аналитичность, естественность). Особого внимания заслуживает то обстоятельство, что креативность как профессионально значимое качество менеджера не попала в этот список. А если учесть, что креативность чаще всего называлась на семинаре как качество, которое хотели бы у себя развить студенты, и соотнести это с данными тестирования, согласно которым у большинства участников проекта имеющийся креативный потенциал пока сдерживается или скрыт для полноценной реализации, то это еще раз указывает на необходимость выделения в качестве специальной образовательной задачи создание условий для развития креативности студентов.

\section{Обсуждение результатов}

Рефлексивный семинар, проводимый с участниками образовательного процесса, позволяет фиксировать и делать предметом рефлексии (с последующим обсуждением) те личностные изменения, которые происходят со студентами и могут быть отнесены как к планируемым (в виде образовательных целей), так и к побочным образовательным эффектам. Неотрефлексированная фиксация на ценностных аспектах обучения может вести к рискам формирования личностных компетенций, т.е. к личностной деградации $[10,11]$.

Феномен актуализации субъективной оценки динамики собственных личностных изменений, являясь, несомненно, ожидаемым и планируемым результатом образовательной деятельности, в то же время может рассматриваться и как диагностический показатель, отражающий индивидуальные варианты протекания процесса профессионального самоопределения.

Совокупность эмпирических данных дает основания для выделения еще одного образовательного феномена - актуализации готовности к пониманию поведенческих реакций партнеров и себя самого. В результате рефлексивных действий студентов в процессе обсуждения происходила актуализация двух встречных процессов: центрации, приводящей к осознанию себя (самооценка), своих оценок, данных другим людям, и децентрации, когда студент оказывается способным увидеть ситуацию глазами других людей (как они оценят). И в этом смысле специально организованный постоянно действующий рефлексивный семинар позволяет создать ситу- 
ацию, в которой взаимообусловленность центрации - децентрации является необходимым условием актуализации готовности к пониманию других и себя.

В целом же, делая заключение о возможностях рефлексивного семинара как способа актуализации образовательных феноменов (как предполагаемых, так и побочных, незапланированных продуктов образовательной деятельности), можно отметить следующее.

1. Основным психологическим содержанием рефлексивной деятельности участников проекта на разных этапах семинара явилась трансформация ценностно-смысловых составляющих образа мира студентов в процессе решения «задач на смысл», «задач на ценность», что открывает новые реальные возможности студентам «поймать» свою собственную субъективность.

2. Динамика процессов смыслообразования, перестройки смыслов участников семинара позволила актуализировать проявления различных аспектов процессов саморазвития, профессионального и личностного самоопределения, выступающих для организаторов психологического сопровождения проекта в качестве образовательных феноменов, модальность которых отражает общую направленность и результативность реализации образовательных программ подобного рода.

3. Выявленный феномен тенденции занижения оценки степени развития профессионально значимых качеств у других по сравнению с самооценкой требует дальнейшего изучения, по крайней мере, в двух аспектах:

а) выяснения того, что проявляется в данном случае - завышение самооценки или занижение оценки другим, т.е. это проблемы самопонимания или проблемы, связанные с восприятием других людей;

б) выяснение того, является ли данный феномен следствием процесса профессиональной подготовки менеджеров или свидетельствует о том, что молодые люди с определенными особенностями выбирают определенные виды профессиональной деятельности.

Тем более что подобные исследования среди студентов, обучающихся по специальностям «психология» и «клиническая психология», такого эффекта не выявили. По сути, речь идет о возможных предпосылках затруднений в общении (коммуникативных барьерах), возникающих вследствие субъективно переживаемого человеком состояния «сбоя» в реализации прогнозируемого (планируемого) общения вследствие неприятия, неадекватного восприятия и понимания партнера общения, его действий, коммуникативной ситуации, собственного состояния и т.д. Если данный феномен действительно может быть отнесен к образовательным эффектам, тогда нужно серьезно ставить вопрос о необходимости введения в программу подготовки менеджеров соответствующего психологического сопровождения, в задачи которого входят профилактика возникновения и коррекция уже возникших предпосылок профессиональных деформаций менеджеров, среди которых особо выделяют авторитарность, демонстративность, доминантность [9]. 
Завершая обсуждение полученных результатов, сделаем несколько важных, с нашей точки зрения, обобщений.

1. В числе функций, которые современная психология обнаруживает в рефлексии как психологическом феномене, особо выделяется функция участия рефлексии в перестройке ценностно-смысловых составляющих образа мира человека. Рефлексия является не ситуативным моментом деятельности, мышления или общения, а одним из условий самоорганизации человека как развивающейся гетеростазической (адаптивно-сверхадаптивной) психологической системы. Рефлексия направлена на постижение смыслов и ценностей предметов, входящих в многомерный мир человека, и открытие в них самого себя, своих истинных потребностей и возможностей, своих истинных мотивов. Результаты рефлексии позволяют человеку представить в идеальном плане сознания связи предметного мира и свою продолженность в этих предметах.

2. Рефлексия, являясь одним из детерминаторов организации творческого мышления, включена в механизм возникновения психологических новообразований, в том числе в процесс «вписывания» новых смыслов и ценностей в образ мира. Высокий уровень развития рефлексии проявляется в перестройке поведения и деятельности, смыслообразовании и перестройке смыслов, поиске вариативных способов решения конкретных проблем, в актах включения человека в творческие процессы, процессы самореализации.

3. Рефлексия обеспечивает открытость человека самому себе, новому опыту, другому человеку и тем самым создает необходимые предпосылки для превращения физического пространства человеческого бытия в пространство возможностей. Реализация рефлексивных возможностей в конкретных ситуациях означает выход за пределы этой ситуации, самостоятельный анализ и принятие собственных решений, что означает устойчивость самоидентификации, рост резистентности по отношению к внешним воздействиям манипулятивного плана. Достаточно продуктивной организационной формой подобной деятельности в условиях образовательного процесса в вузе и являются рефлексивные семинары, цель которых состоит в фиксации как достижений студентов в образовательной системе, так и тех изменений, которые происходят с ними в процессе профессионального обучения (в том числе в направлении формирования образовательной позиции и надпрофессиональных личностных компетенций, необходимых будущим специалистам, таких как умение управлять собой, информацией, умения в межличностном общении и самопрезентации и т.п.), а также в аутентичном оценивании своего личного образовательного опыта и образовательных результатов.

4. Предметом рефлексии молодых людей, зачастую возникающей спонтанно еще на первых этапах профессионального самоопределения, выбора будущей специальности при поступлении в вуз, как правило, является соотнесение представлений о профессионально значимых качествах, которыми необходимо обладать специалисту в той или иной сфере профессиональной деятельности, с представлениями о наличии и степени вы- 
раженности этих качеств у себя. Обучаясь в университете, студенты расширяют, конкретизируют, опредмечивают имеющиеся у них сведения о специфике личностных качеств, значимых для успешного овладения профессией.

5. Если рассматривать в качестве источника саморазвития молодых людей перманентно воспроизводимое несоответствие между образом мира и ценностно-смысловым содержанием учебно-профессиональной деятельности (предельным в котором является отношение к деятельности как способу самореализации, самодвижения), то форма рефлексивного семинара открывает широкие возможности для актуализации потребности в саморазвитии.

\section{Лuтература}

1. Дмитриева T.B., Седова Н.Е. Развитие рефлексии у студентов как педагогическая задача // Вестник Тюменского государственного университета. 2009. № 5. С. 33-42.

2. Дорофеева Н.В. Психологические условия рефлексивного развития на ранних этапах онтогенеза // Психология обучения. 2007. № 9. С. 18-34.

3. Карпов А.В. Психология рефлексивных механизмов деятельности. М. : Институт психологии РАН, 2004. 422 с.

4. Прохоров А.О. Рефлексивный слой психического состояния // Мир психологии. 2006. № 2. C. 39-49.

5. Краснорядиева O.M. Актуальные проблемы психологического сопровождения образовательных проектов // Сибирский психологический журнал. 2005. № 22. С. 129134.

6. Краснорядиева О.М., Трифонова Ю.А. Психолого-образовательное сопровождение процесса становления профессиональной идентичности студентов педагогического колледжа // Психология обучения. 2011. № 11. С. 74-85.

7. Психологические практики диагностики и развития самоэффективности студенческой молодежи : учеб. пособие / О.М. Краснорядцева, В.И. Кабрин, О.И. Муравьева, М.А. Подойницина, О.Н. Чучалова. Томск : Издательский Дом Томского государственного университета, 2014. С. 276.

8. Психодиагностические технологии выявления потенциала инновационности и одаренности молодежи : учеб. пособие / В.Е. Клочко, О.М. Краснорядцева, В.В. Мацута, М.А. Подойницина, О.Н. Стариченко, О.Н. Чучалова. Томск : Издательский Дом Томского государственного университета, 2013. 172 с.

9. Никифоров Г.С., Дмитриева М.А., Снеткова В.М. Практикум по психологии менеджмента и профессиональной деятельности. СПб. : Речь, 2001. 448 с.

10. Лукьянов О.В., Шмырёва М.А. Высокий инновационный потенциал - форма деградации высокого личностного потенциала // Вестник Томского государственного университета. 2012. № 359. С. 157-159.

11. Лукьянов О.В. Управление образовательными рисками - актуальная социальнопсихологическая практика // Сибирский психологический журнал. 2010. № 35. C. $72-76$.

Поступила в редакичию 08.09.2015 г.; принята 05.10.2015 г.

КРАСНОРЯДЦЕВА Ольга Михайловна, доктор психологических наук, профессор, зав. кафедрой общей и педагогической психологии Томского государственного университета (Томск, Россия).

E-mail:krasnoo@mail.ru 


\section{EDUCATIONAL EXPERIENCE OF REFLECTION DEVELOPING IN THE PER- SONAL COMPETENCIES STRUCTURE OF STUDENTS STUDYING MANAGE- MENT}

Siberian journal of psychology, 2015, 58, 45-60. DOI: 10.17223/17267080/58/3

Krasnorjadtseva Olga M. Tomsk State University(Tomsk, Russian Federation).

E-mail: krasnoo@mail.ru

Keywords: reflection; personal competence; "centration-decentration"; educational effects; actualization; reflexive seminar.

The article proposes an approach to the development of reflection skills of managers in professional training. The study was conducted at the Tomsk State University (Tomsk, Russia) with senior students earning a degree in "Management" and who are participants of the interdepartmental educational project "Innovation Projects Management". The total sample group is 126 students. The potential of the reflective seminar as a tool revealing educational phenomena was considered. The approach to understand reflection as a mechanism of personal evaluation of life world, its value-sense composition and occurring changes was argued. The major objectives of the seminar included: development of skills to reflect upon the dynamics of personal changes; development of skills to reflect upon the preparedness and ability to introduce oneself to the project partners in joint project activities and to understand partners' behavioral reactions. Various questionnaire techniques are used to monitor dynamics of personal changes of the seminar's participants. The research data on the phenomenon of centration-decentration as a necessary condition for revelation of readiness to understand the Others and the Self were analyzed. Reflection, being the determinant of organization of creative thinking, is included in the mechanisms of emergence of new psychological formations as well as in the process of "inscribing" new senses and values in the worldview. High level of reflection development becomes apparent in behaviour and activity transformation, in sensemaking and sense transformation, in searching for alternative ways of solution to particular problems, in acts of involvement of a person in creative processes, in self-actualization processes. Comparison of conceptions of professionally significant qualities which are necessary for a professional in a particular field with conceptions of existence and the degree of expression of these qualities in themselves as a rule becomes a subject of the young people's reflection frequently occurring spontaneously at the first stage of professional self-determination, choice of the future profession when entering a university. While studying at the university students broaden horizons, make more specific and objectify their knowledge about particular character of some personal qualities significant for successful professional training and development. If continuously replicated inconsistency between worldview and value-sense contents of learning and professional activity (determining the attitude towards an activity as to the way of self-actualization) is considered as a source of self-development for the young people, then the form of the reflective seminar offers a variety of opportunities to actualize the need for self-development.

\section{References}

1. Dmitrieva, T.V. \& Sedova, N.E. (2009) Razvitie refleksii u studentov kak pedagogicheskaya zadacha [Development of students' reflexion as a pedagogical problem]. Vestnik Tyumenskogo gosudarstvennogo universiteta. 5. pp. 33-42.

2. Dorofeeva, N.V. (2007) Psikhologicheskie usloviya refleksivnogo razvitiya na rannikh etapakh ontogeneza [Psychological conditions of reflective development in the early stages of ontogenesis]. Psikhologiya obucheniya - Psychology of Education. 9. pp. 18-34.

3. Karpov, A.V. (2004) Psikhologiya refleksivnykh mekhanizmov deyatel'nosti [Psychology of reflexive mechanisms of action]. Moscow: Institute of Psychology RAS. 
4. Prokhorov, A.O. (2006) Refleksivnyy sloy psikhicheskogo sostoyaniya [Reflective layer of a mental condition]. Mir psikhologii. 2. pp. 39-49.

5. Krasnoryadtseva, O.M. (2005) Aktual'nye problemy psikhologicheskogo soprovozhdeniya obrazovatel'nykh proektov [Topical problems of psychological support for educational projects]. Sibirskiy psikhologicheskiy zhurnal - Siberian Journal of Psychology. 22. pp. 129-134.

6. Krasnoryadtseva, O.M. \& Trifonova, Yu.A. (2011) Psikhologo-obrazovatel'noe soprovozhdenie protsessa stanovleniya professional'noy identichnosti studentov pedagogicheskogo kolledzha [Psychological and educational support of the formation of pedagogocal students' professional identity]. Psikhologiya obucheniya - Psychology of Education. 11. pp. 74-85.

7. Krasnoryadtseva, O.M., Kabrin, V.I., Murav'eva, O.I., Podoynitsina, M.A. \& Chuchalova, O.N. (2014) Psikhologicheskie praktiki diagnostiki i razvitiya samoeffektivnosti studencheskoy molodezhi [Psychological practices of diagnosing and development of students' self-efficacy]. Tomsk: Tomsk State University.

8. Klochko, V.E., Krasnoryadtseva, O.M., Matsuta, V.V., Podoynitsina, M.A., Starichenko, O.N. \& Chuchalova, O.N. (2013) Psikhodiagnosticheskie tekhnologii vyyavleniya potentsiala innovatsionnocti $i$ odarennosti molodezhi [Psychodiagnostic techniques to identify potential of innovativeness and giftedness in the youth]. Tomsk: Tomsk State University.

9. Nikiforov, G.S., Dmitrieva, M.A. \& Snetkova, V.M. (2001) Praktikum po psikhologii menedzhmenta i professional'noy deyatel'nosti [Psychology of management and professional activities]. St. Petersburg: Rech'.

10. Luk'yanov, O.V. \& Shmyreva, M.A. (2012) High innovative potential as high individual potential degradation form. Vestnik Tomskogo gosudarstvennogo universiteta - Tomsk State University Journal. 359. pp. 157-159. (In Russian).

11. Luk'yanov, O.V. (2010) Management in educational risks - actual sociological and psychological practice. Sibirskiy psikhologicheskiy zhurnal - Siberian Journal of Psychology. 35. pp. 72-76. (In Russian). 